\title{
Hidradenitis Suppurativa: Current Understanding of Pathogenic Mechanisms and Suggestion for Treatment Algorithm
}

\author{
S. Morteza Seyed Jafari ${ }^{*}$, Robert E. Hunger and Christoph Schlapbach \\ Department of Dermatology, Inselspital, Bern University Hospital, Bern, Switzerland
}

Hidradenitis suppurativa is one of the most distressing dermatological conditions and has a significant negative impact on patients' quality of life. However, the exact pathogenic mechanisms remain incompletely understood and - therefore - efficient therapies are still lacking. The current manuscript focuses on new findings on its pathogenic mechanisms and aims to provide practical therapy recommendations.

Keywords: hidradenitis suppurativa, pathomechanism, pathogenesis, therapy, treatment

OPEN ACCESS

Edited by:

Hans Christian Ring,

Bispebjerg Hospital, Denmark

Reviewed by:

Rune Kjærsgaard Andersen,

University of Copenhagen, Denmark

Zrinka Bukvic Mokos,

University Hospital Centre

Zagreb, Croatia

*Correspondence:

S. Morteza Seyed Jafari

seyedjafarism@yahoo.com

Specialty section:

This article was submitted to

Dermatology,

a section of the journa

Frontiers in Medicine

Received: 18 November 2019

Accepted: 14 February 2020

Published: 04 March 2020

Citation:

Seyed Jafari SM, Hunger RE and Schlapbach C (2020) Hidradenitis

Suppurativa: Current Understanding of Pathogenic Mechanisms and

Suggestion for Treatment Algorithm.

Front. Med. 7:68.

doi: 10.3389/fmed.2020.00068

\section{INTRODUCTION}

Hidradenitis suppurativa (HS) is a chronic skin disorder, which profoundly decrease quality of life because of emotional, physical and psychologic consequences (1-6). This recurrent inflammatory skin condition with an estimated prevalence of $1-4 \%$ is more frequent in women $(2,5,7,8)$. Most frequently, the age of onset is between 20 and 40 years of life, although postmenopausal women and prepubertal children with new-onset HS have been reported $(2,5,9,10)$. The clinical manifestations range from inflamed nodules and abscesses to draining sinus tracts and formation of scars $(5,11,12)$. The pain, drainage, malodor, and disfigurement associated with HS all contribute to the remarkable psychosocial impact of the disease with negative effects on the patients' quality of life that cannot be overestimated $(5,11,12)$. In fact, HS is associated with an increased risk of completed suicide, an increased risk of adverse cardiovascular outcomes and increased all-cause mortality independent of measured confounders $(13,14)$. Unfortunately, the exact pathogenesis of HS remains unclear. Despite the existence of multiple therapeutic approaches and combinational treatments, effective management of moderate to severe HS remains elusive in many cases. In this manuscript, we summarize the current knowledge about pathophysiology and treatment of HS.

\section{PATHOGENESIS}

\section{Mechanism}

The precise pathogenesis of HS remains still unclear. This chronic skin disorder might be caused by genetic, endocrine, environmental, and microbiological factors (15). The primary event in disease development is thought to be follicular occlusion, based on histopathological observations in very early lesions $(16,17)$. Follicular occlusion is likely due to infundibular keratosis and hyperplasia of the follicular epithelium, which leads to accumulation of cellular debris and formation of cysts $(16,18-20)$. The hair follicle eventually ruptures, followed by release of follicular contents to the dermis, which induces a significant expression of inflammatory mediators and recruitment of inflammatory cells. The end results are abscess formation, painful inflammation and sinus tract formation and scarring, in later stages $(16,18-20)$. 


\section{Genetics}

Two main observations point to a genetic background of HS. First, approximately one third of HS patients have at least one family member also suffering from HS, suggesting an inheritable genetic predisposition (21). Second, families with several mutations or changes in genes of the gamma-secretase family (including nicastrin (NCSTN), presenilin 1 (PSEN1), presenilin enhancer 2 (PSENEN) gene mutation) show an autosomal dominant inheritance of HS, indicating a pathogenic role of these genes in HS (22-26). The resulting alteration in $\gamma$ secretase function might result in HS by affecting downstream Notch signaling in the skin (23).

However, these patients show a severe disease phenotype not entirely typical of "sporadic" HS, raising questions as to what degree this genetic background is representative for all cases of HS. Nevertheless, taken together current evidence strongly supports a genetic predisposition for HS development.

\section{Inflammatory Pathways in Hidradenitis Suppurativa}

The excessive inflammatory response seen in lesional skin of HS is thought to be triggered by a combination of genetic, anatomical, immunological, and environmental factors $(27,28)$. Increased activity of dendritic cells and $\mathrm{T}$ cells cause keratinocyte hyperplasia via the actions of IL-23 and IL-12 and a Th17 immune response (27-30). As HS progresses, increased levels of interleukin (IL)-1, tumor necrosis factor (TNF), IL-17, caspase1, S100A8, S100A9, and IL-10 appear in the tissue together with a recruitment of neutrophils, mast cells and monocytes (16, 27, $28,31-34)$. Recent evidence further points to autoinflammatory mechanism in HS. HS skin shows increased formation of neutrophil extracellular traps (NET). Intriguingly, immune responses to neutrophil and NET-related antigens have been linked to enhanced immune dysregulation and inflammation (35). In combination with the strong type I IFN signature in HS skin, these findings suggest a key involvement of the innate immune response in the pathogenesis of HS (36). As healing from the remarkable inflamation progresses, tunneling and scarring of the tissue occur $(27,28,31)$. The development of sinus tracts and scarring is associated with matrix metalloproteinase-2 (MMP2 ), transforming growth factor beta (TGF- $\beta$ ) and (Intercellular adhesion molecule-1 (ICAM-1), with possible augmentation of TGF- $\beta$ and ICAM-1 signaling via specific components of the microbiome $(27,28)$.

\section{Bacteria}

Bacterial involvement in HS pathogenesis remains highly debated $(37,38)$. A number of studies have shown that cultures of HS lesions are predominately sterile or contain only commensal skin flora $(38,39)$. As a result, primary infection is viewed as an unlikely cause of HS $(38,39)$. In addition, the lack of strong therapeutic effect of antibiotic treatment further argues against a primary infectious cause (40). However, it is still possible that microbial "dysbiosis" and an altered skin microbiome are important factors contributing to HS pathogenesis. In fact, the cutaneous microbiome in patients with HS is substantially different from that of normal donors. A variety of partly overrepresented, partly unique species have been isolated from HS lesions and linked to various features of the disease (41, 42). Yet, their pathogenetic contribution has remained elusive, in large part because of the technical and experimental difficulties of investigating their causal role in humans (38, 42). Furthermore, the microanatomical intricacies of HS skin with its fistulas and sinus tracts represent an important basis for biofilm formation, bacterial colonization, and secondary infection, which contribute to disease exacerbations, suppuration and extension of lesions $(38,43)$. Although the role of bacterial biofilm in HS is highly debated, the association between biofilm and the number of regulatory $\mathrm{T}$ cells (TREG) in a recent study supports the concept of dysbiosis as a factor in the preclinical HS lesions (44). In summary, microbial colonization and infection are likely pathogenic contributors to HS, but it is still unclear if the colonization of bacteria is a primary or secondary event in the evolution of HS (37). Since the follicular infundibulum is populated by a broad microbiome, deficiencies in the follicular skin immune system might cause microbial overgrowth. However, another theories suggest that an overactive immune system might contribute to a remarkable inflammatory response to harmless, normal flora (16).

\section{Other Associated Factors}

Mechanical stress (45), metabolic syndrome $(2,37,38)$, diet (46), smoking (2, 38), and hormonal factors (47) have been reported in previous studies to contribute to the development or exacerbation of HS. While the epidemiological evidence for this is undisputed, at least for some factors such as smoking and obesity, the mechanism by which these factors contribute to HS pathogenesis remain far from clear. Smoking, for instance, is one of the best-documented behavioral risk factors for HS, but the mechanisms by which it triggers HS is poorly understood. There are thousands of chemicals in tobacco smoke, which have the potential to activate keratinocytes, fibroblasts, and immune cells. Mechanistically, these substances may trigger skin cells via two types of receptors: aryl hydrocarbon receptors and nicotinic acetylcholine receptors $(16,48,49)$. In keratinocytes, activation of these receptors can lead to infundibular epithelial hyperplasia, acanthosis and excessive cornification $(16,49)$. Furthermore, tobacco smoke can induce expression of proinflammatory cytokines such as TNF-a, IL-8, IL- $1 \alpha$, and IL- $1 \beta$ leading to neutrophil chemotaxis, altered function of TREG, as well as activation of Th17 pathways (16, 27, 50-53). Other important risk factors for HS, obesity and diabetes, can also result in overproduction of TNF- $\alpha$, IL- $1 \beta$, and IL- 6 through activated macrophages in adipose tissue $(27,51-53)$. In addition, obesity can worsen HS through increased skin-clothing and skin-skin friction, as mechanical stress can increase follicular occlusion and rupture $(16,45)$.

Hormones are also thought to be involved in HS pathogenesis. This is primarily based on a number of clinical observations and promising effects of antiandrogen treatments. For instance, some female HS patients observe worsening of disease in conjunction with menstruation or after starting hormonal contraception with androgen effects (e.g., progesterone-containing drugs) $(47,54)$. Hormones can induce occlusion and plugging of 
the follicle and increase production and composition of sebum, thereby contributing to the vicious cycle of HS skin inflammation $(55,56)$.

\section{Suggested Therapy Approach Based on the Current Knowledge}

There is no single efficient therapy for the skin disorder. As a result, clinicians typically should choose from different treatment modalities and often have to combine them to achieve disease control. The choice of treatment depends on the distribution and overall severity of disease, the anatomic location and inflammatory activity of the lesions, the patient's comorbidities, as well as treatment cost and availability (2, $5,9,38)$. In order to assess the severity and extent of hidradenitis suppurativa various scoring systems are in common use: hurley stages, sartorius hidradenitis suppurativa score, hidradenitis suppurativa physician global assessment (HS-PGA) and hidradenitis suppurativa clinical response (HiSCR) (57-59).
HS management is often complex. The standard of care management requires an individualized approach in a multifaceted approach, ranging from self-management (e.g., avoidance of skin trauma, pain management, smoking cessation, weight loss and hygiene practices) to local therapies, systemic antibiotics, and a wide range of immunomodulating agents, as well as surgical interventions such as excisional and laser surgeries $(6,15,38,39,60)$. Additionally, the diagnosis and management of medical comorbidities and referral to psychiatrist might be taken into consideration (61). An overview of a suggested multidimensional approach is summarized in Figure 1.

\section{Life Style Modification}

Because smoking and obesity have the greatest association with the severity of the disease, it is recommended that patients with HS stop smoking and reduce their body weight. In addition, loose-fitting clothing in order is advised to avoid friction and

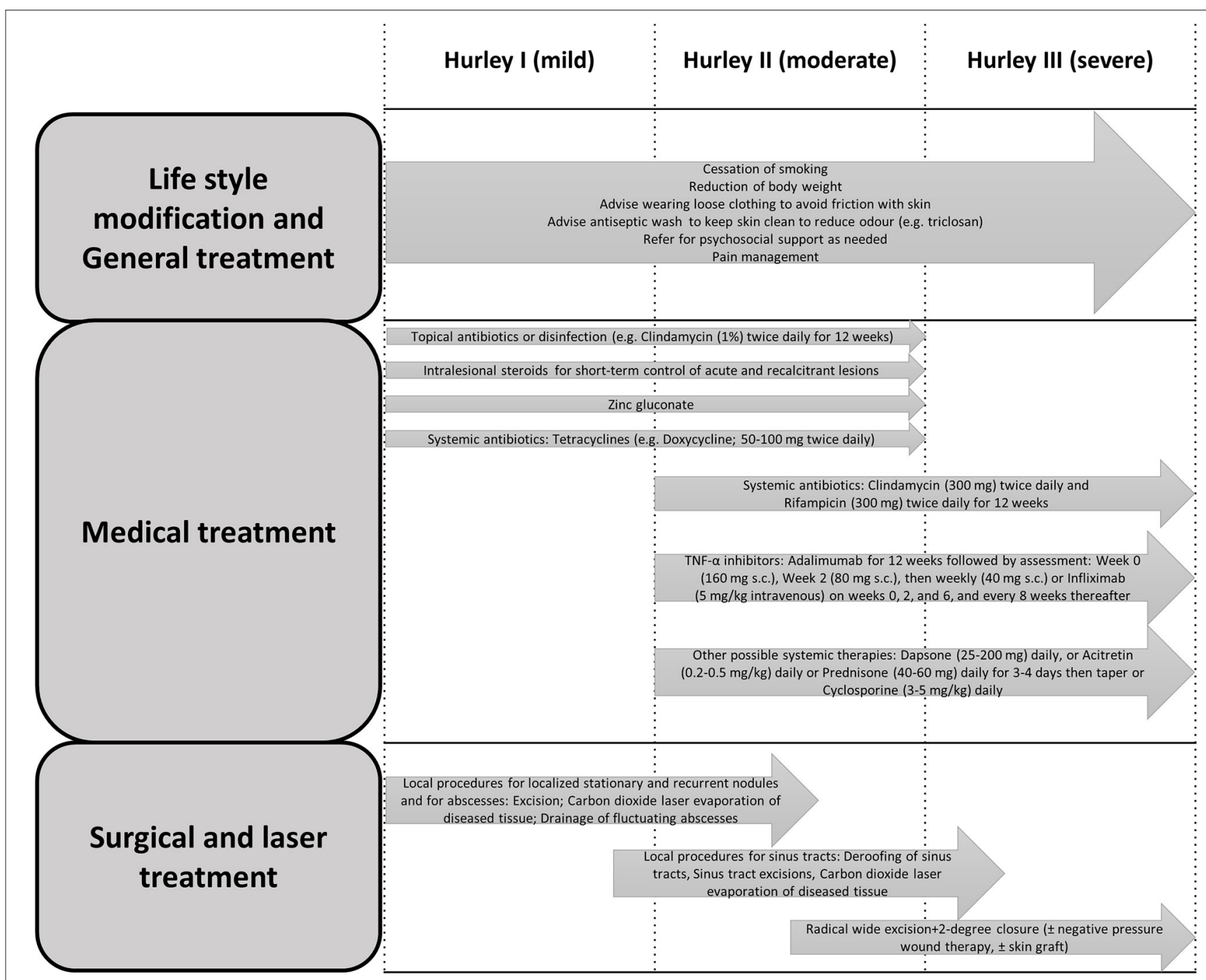

FIGURE 1 | Clinical practice recommendations for the treatment of HS, modified from Hunger et al. and Saunte and Jemec (15, 31). 
mechanical stress $(2,6,15)$. Zinc might be suggested for patients with Hurley stage I-II, as an innate immunity modulator $(6,62)$.

\section{Pain Management}

Acute and chronic pain is a remarkable contributor to quality of life in individuals with HS, and reduction of inflammation can improve the pain $(6,63)$. Depression, which plays a crucial role in the perception of pain, is a risk factor for the development of chronic pain in these patients $(6,17,63)$. Managing HS pain is complicated. Therefore, a multidisciplinary approach, including pain assessment, pain scoring, and the involvement of a pain specialist, is warranted $(6,17)$. A variety of alternatives are reported in the recent studies, such as local analgesics, non-steroidal paracetamol, anti-inflammatory drugs, pregabalin, gabapentin, venlafaxine, and duloxetine (17). In more complex cases may require the judicious use of antidepressants (64). In selected patients with severe pain, careful administration of individualized, short-acting opioid analgesics might be necessary $(6,17)$.

\section{Local Therapy and Wound Care}

Local treatment of this chronic disorder includes antiseptic washes, keratolytic agents and topical antibiotics $(6,60)$. Selection of dressing is based on the location, skin condition, amount of drainage, cost and patient preference $(6,60)$. For local treatment of selected large open wounds, use of negative-pressure therapy for a short period of time (1-4 weeks) followed by delayed reconstruction might be effective (6). Clinical experience supported the use of Intralesional corticosteroid injection (e.g., triamcinolone 3-5 mg) only for short-term control of acute and recalcitrant HS lesions $(60,65)$. Pain is typically reduced fast and a reduction in edema, erythema, suppuration and lesion size occur after a few days. However, the long-term efficacy of this approach remains unclear and local side effects, most notably skin atrophy, have to be carefully monitored $(31,65)$.

\section{Antibiotics}

Available evidence-based literature on the administration of antibiotics in this disorder is limited and mostly restricted to retrospective studies (66). Determining the frequency and duration of antibiotic use should balance of antibiotic use vs. potential harms associated with antibiotic resistance, because findings of recent studies stated that antibiotic therapy for HS treatment might be inducing antibiotic resistance (67). Typically, HS recurs following cessation of antibiotic therapy, making repeated or long-term treatments necessary, with all their potential harmful side effects (60). For Hurley stage III, especially in the absence of abscesses, topical clindamycin $1 \%$ is a possible therapy $(60,66,68,69)$. However, it carries a high risk of bacterial resistance $(60,66,68,69)$. If there are frequent exacerbations and/or several lesions the administration of systemic antibiotics can be recommended $(66,69)$. For example, tetracyclines (e.g., doxycycline 50-100 twice daily) are considered in mild-to-moderate HS for a 12-weeks course or as a long-term maintenance alternative, when appropriate (60). For the patients with Hurley stage II-III systemic clindamycin and rifampicin ( $300 \mathrm{mg}$ twice daily) could be suggested as a second-line therapy for mild-to-moderate HS or as a first-line or adjunct therapy in the patients with severe disease $(60,66$, $70,71)$. A triple regimen of moxifloxacin ( $400 \mathrm{mg}$ once daily), rifampicin $(10 \mathrm{mg} / \mathrm{kg}$ once daily) and metronidazole $(500 \mathrm{mg}$ thrice daily) administered for up to 12 weeks, with metronidazole discontinuation after 6 weeks, might be considered as secondor third-line alternative therapy in moderate-to-severe disease $(60,66)$. Dapsone might be recommended as an effective and safe alternative therapeutic option for a minority of patients as long-term maintenance therapy $(60,72,73)$. The effect could be due to either its anti-inflammatory or antibacterial effects, or both. However, rapid recurrence after stopping the therapy suggests that its anti-inflammatory effects are possible more prominent $(60,72)$.

\section{Other Systemic Therapies}

A short-term systemic corticosteroid therapy could be recommended for acute conditions or to bridge to other treatments (60). However, long-term systemic steroid therapy tapered to the lowest possible dose might be an alternative option for the patients with severe disease, as an adjunct therapy in patients without sufficient response to standard recommended therapies (60). Hormonal agents, such as estrogen-containing combined oral contraceptives cyproterone acetate, spironolactone, metformin, and finasteride, might be recommended in the female patients, either as monotherapy for mild-to-moderate disease or in combination with other treatments for severe HS $(60,74-77)$. Isotretinoin could be recommended only as a second- or third-line treatment or in patients with concomitant acne $(60,78,79)$. Cyclosporine might be considered in cases of moderate-to-severe disease who have failed or are not suitable for other therapies $(60,80)$. Recent studies do not recommend the administration of azathioprine or methotrexate in the treatment of HS $(60,81,82)$.

\section{Administration of Biologics in HS}

Immunomodulation is becoming popular for moderate-to-severe form of the disease. Targeting the tumor necrosis factor (TNF), interleukin 1 (IL-1), IL-12, and IL-23 has been considered as potential therapies $(60,83)$.

Adalimumab is recommended as the first-line biologic therapy for moderate-to-severe HS $(60,66)$, followed by Infliximab and anakinra as second- and third-line options, respectively $(66,84,85)$. The recommended dose of adalimumab in HS is $160 \mathrm{mg}$ on Week $0,80 \mathrm{mg}$ on Week 2 and then $40 \mathrm{mg}$ weekly $(60,66)$. Recent studies suggest that those patients who do not respond to therapy within 12 weeks $(<25 \%$ improvement in inflammatory nodules and abscesses) should discontinue the drug $(66,86-89)$. However, the patients with partial or good should continue the therapy with ongoing assessment (66, 86-89).

Evidence is lacking for other biologic therapies, and any clinical decisions should be based on close monitoring and risk: benefit assessments (66). Recent studies showed administration of other biologics such as other TNF-alpha blockers (66, 9092), ustekinumab, (93-96) secukinumab, $(97,98)$ bimekizumab, (99) canakinumab, $(3,100)$ apremilast, $(1,101)$ anakinra, (102) 
guselkumab (103, 104), and rituximab (105) in management of HS.

Most biologics are well-tolerated and show a favorable safety profile in the short- to medium-term. However, long-term safety concerns, including infection risks, the development of malignancy and demyelinating disorders should be to assessed (19). These issues are remarkable in the treatment of HS, where the biologics dosing is generally higher in comparison to other inflammatory skin disorders such as psoriasis. As a result, patient selection is crucial, because complete response is not the norm and not all patients tolerate or respond well to these therapies. Critical monitoring of therapy effects and side effects has to be carefully done under treatment to inform continuous risk-benefit assessment. In case of unfavorable outcome of such assessment, other treatment modalities have to be taken into consideration, such as surgery (19).

\section{Surgical Modalities}

Planning of type of surgery and required margins should be cleared in cooperation with the patient and based on the severity of the disease $(15,39,66)$. Local excision of single lesions is only suggested in well-circumscribed, localized cases of Hurley I-II (15). For painful abscesses, no medical therapy will be effective $(6,15,43,66,106,107)$. Therefore, surgical drainage might be demanded to relieve pain; however, this should not be considered as sole treatment, because recurrence is most of the patients inevitable $(6,15,43,66,106,107)$. Extensive excision, electrosurgical excision (with or without reconstruction) $\mathrm{CO}_{2}$ laser could be appropriate for chronic lesions to prevent recurrence $(5,6,66,108-111)$. Wound healing following surgery may be through primary closure, delayed primary closure, secondary intention, grafts, flaps, and/or skin substitutes $(5,6,66,108-111)$. Furthermore, a new surgical approach was described recently, the step-by-step surgery, which consists in consecutively removing portions of HS skin with secondary intention healing (112). Recent studies suggest that continuing medical therapy in the perioperative period might be beneficial and reduce risk of postoperative complications (6).

\section{Laser Therapy}

Most of laser therapies have been focused of modification of disease activity in the groin and axillae, because, the destruction of the pilosebaceous apparatus might prevent the extension of disease (17). Neodymium-doped yttrium aluminum garnet

\section{REFERENCES}

1. Weber P, Seyed Jafari SM, Yawalkar N, Hunger RE. Apremilast in the treatment of moderate to severe hidradenitis suppurativa: a case series of 9 patients. J Am Acad Dermatol. (2017) 76:1189-91. doi: 10.1016/j.jaad.2017.02.026

2. Seyed Jafari SM, Knusel E, Cazzaniga S, Hunger RE. A retrospective cohort study on patients with hidradenitis suppurativa. Dermatology. (2018) 234:71-8. doi: 10.1159/000488344

3. Houriet C, Seyed Jafari SM, Thomi R, Schlapbach C, Borradori L, Yawalkar N, et al. Canakinumab for severe hidradenitis suppurativa: preliminary experience in 2 cases. JAMA Dermatol. (2017) 153:11957. doi: 10.1001/jamadermatol.2017.2392
(Nd:YAG) laser is applicable for Hurley stage II-III disease (6, $17,39)$. Furthermore, $\mathrm{CO}_{2}$ laser excision can be considered in patients with Hurley stage II-III with fibrotic sinus tracts (6).

\section{CONCLUSIONS}

In conclusion, HS is characterized by a pathological reaction pattern of the follicular epithelium of the apocrine glandbearing skin to yet ill-defined insults. As a result, the follicular epithelium becomes hyperplastic, showing hyperkeratosis of the infundibulum, follicular occlusion, and cyst formation. Rupture of such cysts and consecutive invasion of follicular material into the dermis is likely a key step in triggering a remarkable immune response, which lies at the heart of painful inflammation and abscess formation. In later stages, uncontrolled inflammation leads to sinus tract formation and scarring. There is no uniformly effective therapy for HS. As a result, clinicians should take a multifaceted approach depending on the patients' needs and on features of the disease. Therapy modalities range from selfmanagement and topical treatments to systemic antibiotics, immunomodulating agents, as well as surgical interventions. All in all, it is recommended to avoid the trigger factors such as: smoking, obesity, mechanical friction and shaving. Furthermore, local disinfectants and/or topical antibiotics are suggested in order avoid bacterial superinfections and reduce inflammation. If topical agents are not sufficient, systemic antibiotics are typically given. If antibiotics are not sufficient or no longer effective, other systemic therapies (e.g., adalimumab, dapsone, systemic steroids, or cyclosporine) might be used in patients with refractory disease. Additionally, if needed different surgical interventions might be taken into consideration in cooperation with the patient and based on the severity of the disease.

\section{AUTHOR CONTRIBUTIONS}

SS, RH, and CS designed the study and performed acquisition, analysis, interpretation of data, and wrote the manuscript, and performed critical revision of the manuscript for important intellectual content.

\section{FUNDING}

This study was supported by the Peter Hans Hofschneider Professorship for Molecular Medicine (to CS).

4. Deckers IE, van der Zee HH, Prens EP. Severe fatigue based on anaemia in patients with hidradenitis suppurativa: report of two cases and a review of the literature. J Eur Acad Dermatol Venereol. (2016) 30:1745. doi: $10.1111 /$ jdv. 12680

5. Jemec GB, Heidenheim M, Nielsen NH. Hidradenitis suppurativacharacteristics and consequences. Clin Exp Dermatol. (1996) 21:41923. doi: 10.1111/j.1365-2230.1996.tb00145.x

6. Alikhan A, Sayed C, Alavi A, Alhusayen R, Brassard A, Burkhart C, et al. North American clinical management guidelines for hidradenitis suppurativa: a publication from the United States and Canadian Hidradenitis Suppurativa Foundations: part I: diagnosis, evaluation, and the use of complementary and procedural management. J Am Acad Dermatol. (2019) 81:76-90. doi: 10.1016/j.jaad.2019.02.067 
7. Garg A, Kirby JS, Lavian J, Lin G, Strunk A. Sex- and ageadjusted population analysis of prevalence estimates for hidradenitis suppurativa in the United States. J JAMA Dermatol. (2017) 153:760-4. doi: 10.1001/jamadermatol.2017.0201

8. Ingram JR, Jenkins-Jones S, Knipe DW, Morgan CLI, Cannings-John R, Piguet V. Population-based Clinical Practice Research Datalink study using algorithm modelling to identify the true burden of hidradenitis suppurativa. Br J Dermatol. (2018)178:917-24. doi: 10.1111/bjd.16101

9. Alikhan A, Lynch PJ, Eisen DB. Hidradenitis suppurativa: a comprehensive review. J Am Acad Dermatol. (2009) 60:539-61:5623. doi: 10.1016/j.jaad.2008.11.911

10. Garg A, Lavian J, Lin G, Strunk A, Alloo A. Incidence of hidradenitis suppurativa in the United States: a sex- and age-adjusted population analysis. J Am Acad Dermatol. (2017) 77:118-22. doi: 10.1016/j.jaad.2017.02.005

11. Kouris A, Platsidaki E, Christodoulou C, Efstathiou V, Dessinioti C, Tzanetakou V, et al. Quality of life and psychosocial implications in patients with hidradenitis suppurativa. Dermatology. (2016) 232:68791. doi: 10.1159/000453355

12. Wolkenstein P, Loundou A, Barrau K, Auquier P, Revuz J. Quality of life impairment in hidradenitis suppurativa: a study of 61 cases. J Am Acad Dermatol. (2007) 56:621-3. doi: 10.1016/j.jaad.2006.08.061

13. Egeberg A, Gislason GH, Hansen PR. Risk of major adverse cardiovascular events and all-cause mortality in patients with hidradenitis suppurativa. JAMA Dermatol. (2016) 152:429-34. doi: 10.1001/jamadermatol.2015.6264

14. Thorlacius L, Cohen AD, Gislason GH, Jemec GBE, Egeberg A. Increased suicide risk in patients with hidradenitis suppurativa. J Invest Dermatol. (2018) 138:52-7. doi: 10.1016/j.jid.2017.09.008

15. Hunger RE, Laffitte E, Lauchli S, Mainetti C, Muhlstadt M, Schiller $\mathrm{P}$, et al. Swiss practice recommendations for the management of hidradenitis suppurativa/acne inversa. Dermatology. (2017) 233:1139. doi: 10.1159/000477459

16. Prens E, Deckers I. Pathophysiology of hidradenitis suppurativa: an update. J Am Acad Dermatol. (2015) 73:S8-11. doi: 10.1016/j.jaad.2015.07.045

17. Vekic DA, Cains GD. Hidradenitis suppurativa-Management, comorbidities, and monitoring. Aust Fam Physician. (2017) 46:584-8.

18. von Laffert $M$, Stadie V, Wohlrab J, Marsch WC. Hidradenitis suppurativa/acne inversa: bilocated epithelial hyperplasia with very different sequelae. Br J Dermatol. (2011) 164:36771. doi: 10.1111/j.1365-2133.2010.10034.x

19. Lim SYD, Oon HH. Systematic review of immunomodulatory therapies for hidradenitis suppurativa. Biologics. (2019) 13:53-78. doi: 10.2147/BTT.S199862.eCollection 2019

20. Napolitano M, Megna M, Timoshchuk EA, Patruno C, Balato N, Fabbrocini G, et al. Hidradenitis suppurativa: from pathogenesis to diagnosis and treatment. Clin Cosmet Investig Dermatol. (2017) 10:105-15. doi: 10.2147/CCID.S111019.eCollection 2017

21. Canoui-Poitrine F, Le Thuaut A, Revuz JE, Viallette C, Gabison G, Poli $F$, et al. Identification of three hidradenitis suppurativa phenotypes: latent class analysis of a cross-sectional study. J Invest Dermatol. (2013) 133:150611. doi: $10.1038 /$ jid.2012.472

22. Ingram JR. The genetics of hidradenitis suppurativa. Dermatol Clin. (2016) 34:23-8. doi: 10.1016/j.det.2015.07.002

23. Pink AE, Simpson MA, Desai N, Trembath RC, Barker JNW. $\gamma$ Secretase mutations in hidradenitis suppurativa: new insights into disease pathogenesis. J Invest Dermatol. (2013) 133:601-7. doi: 10.1038/jid.2012.372

24. Pink AE, Simpson MA, Desai N, Dafou D, Hills A, Mortimer P, et al. Mutations in the $\gamma$-secretase genes NCSTN, PSENEN, and PSEN1 underlie rare forms of hidradenitis suppurativa (acne inversa). J Invest Dermatol. (2012) 132:2459-61. doi: 10.1038/jid.2012.162

25. Wang B, Yang W, Wen W, Sun J, Su B, Liu B, et al. Gammasecretase gene mutations in familial acne inversa. Science. (2010) 330:1065. doi: 10.1126/science.1196284

26. Li A, Peng Y, Taiclet LM, Tanzi RE. Analysis of hidradenitis suppurativalinked mutations in four genes and the effects of PSEN1-P242LfsX11 on cytokine and chemokine expression in macrophages. Hum Mol Genet. (2019) 28:1173-82. doi: 10.1093/hmg/ddy414

27. Frew JW, Hawkes JE, Krueger JG. A systematic review and critical evaluation of inflammatory cytokine associations in hidradenitis suppurativa. F1000Res. (2018) 7:1930. doi: 10.12688/f1000research.1 7267.1

28. Thomi R, Cazzaniga S, Seyed Jafari SM, Schlapbach C, Hunger RE. Association of hidradenitis suppurativa with $\mathrm{T}$ helper 1/T helper 17 phenotypes. JAMA Dermatol. (2018) 154:5925. doi: 10.1001/jamadermatol.2018.0141

29. Thomi R, Schlapbach C, Yawalkar N, Simon D, Yerly D, Hunger RE. Elevated levels of the antimicrobial peptide LL-37 in hidradenitis suppurativa are associated with a Th1/Th17 immune response. Exp Dermatol. (2018) 27:172-7. doi: 10.1111/exd.13482

30. Schlapbach C, Hanni T, Yawalkar N, Hunger RE. Expression of the IL-23/Th17 pathway in lesions of hidradenitis suppurativa. J Am Acad Dermatol. (2011) 65:790-8. doi: 10.1016/j.jaad.2010.07.010

31. Saunte DML, Jemec GBE. Hidradenitis suppurativa: advances in diagnosis and treatment. JAMA. (2017) 318:2019-32. doi: 10.1001/jama.2017.16691

32. Hotz C, Boniotto M, Guguin A, Surenaud M, Jean-Louis F, Tisserand $\mathrm{P}$, et al. Intrinsic defect in keratinocyte function leads to inflammation in hidradenitis suppurativa. J Invest Dermatol. (2016) 136:1768-80. doi: 10.1016/j.jid.2016.04.036

33. van der Zee $\mathrm{HH}$, de Ruiter L, van den Broecke DG, Dik WA, Laman JD, Prens EP. Elevated levels of tumour necrosis factor (TNF)$\alpha$, interleukin (IL)-1 $\beta$ and IL-10 in hidradenitis suppurativa skin: a rationale for targeting TNF- $\alpha$ and IL-1 $\beta$. Br J Dermatol. (2011) 164:12928. doi: 10.1111/j.1365-2133.2011.10254.x

34. Kelly G, Hughes R, McGarry T, van den Born M, Adamzik K, Fitzgerald R, et al. Dysregulated cytokine expression in lesional and nonlesional skin in hidradenitis suppurativa. Br J Dermatol. (2015) 173:14319. doi: 10.1111/bjd.14075

35. Byrd AS, Carmona-Rivera C, O’Neil LJ, Carlucci PM, Cisar C, Rosenberg AZ, et al. Neutrophil extracellular traps, B cells, and type I interferons contribute to immune dysregulation in hidradenitis suppurativa. Sci Transl Med. (2019) 11:5908. doi: 10.1126/scitranslmed.aav5908

36. Shanmugam VK, Jones D, McNish S, Bendall ML, Crandall KA. Transcriptome patterns in hidradenitis suppurativa: support for the role of antimicrobial peptides and interferon pathways in disease pathogenesis. Clin Exp Dermatol. (2019) 44:882-92. doi: 10.1111/ced.13959

37. Ring HC, Riis Mikkelsen P, Miller IM, Jenssen H, Fuursted K, Saunte DM, et al. The bacteriology of hidradenitis suppurativa: a systematic review. Exp Dermatol. (2015) 24:727-31. doi: 10.1111/exd.12793

38. Vinkel C, Thomsen SF. Hidradenitis suppurativa: causes, features, and current treatments. J Clin Aesthet Dermatol. (2018) 11:17-23

39. Zouboulis CC, Desai N, Emtestam L, Hunger RE, Ioannides D, Juhasz I, et al. European S1 guideline for the treatment of hidradenitis suppurativa/acne inversa. J Eur Acad Dermatol Venereol. (2015) 29:61944. doi: $10.1111 /$ jdv. 12966

40. Naik HB, Nassif A, Ramesh MS, Schultz G, Piguet V, Alavi A, et al. Are bacteria infectious pathogens in hidradenitis suppurativa? debate at the symposium for hidradenitis suppurativa advances meeting, November 2017. J Invest Dermatol. (2019) 139:13-16. doi: 10.1016/j.jid.2018.09.036

41. Ring HC, Thorsen J, Saunte DM, Lilje B, Bay L, Riis PT, et al. The follicular skin microbiome in patients with hidradenitis suppurativa and healthy controls. JAMA Dermatol. (2017) 153:897-905. doi: 10.1001/jamadermatol.2017.0904

42. Ring HC, Bay L, Kallenbach K, Miller IM, Prens E, Saunte DM, et al. Normal skin microbiota is altered in pre-clinical hidradenitis suppurativa. Acta Derm Venereol. (2017) 97:208-13. doi: 10.2340/00015555-2503

43. Revuz J. Hidradenitis suppurativa. J Eur Acad Dermatol Venereol. (2009) 23:985-98. doi: 10.1111/j.1468-3083.2009.03356.x

44. Kjaersgaard Andersen R, Ring HC, Kallenbach K, Eriksen JO, Jemec GBE. Bacterial biofilm is associated with higher levels of regulatory $\mathrm{T}$ cells in unaffected hidradenitis suppurativa skin. Exp Dermatol. (2019) 28:3126. doi: 10.1111/exd.13885

45. Boer J, Jemec GB. Mechanical stress and the development of pseudocomedones and tunnels in Hidradenitis suppurativa/Acne inversa. Exp Dermatol. (2016) 25:396-7. doi: 10.1111/exd.12926

46. Danby FW. Diet in the prevention of hidradenitis suppurativa (acne inversa). J Am Acad Dermatol. (2015) 73:S52-4. doi: 10.1016/j.jaad.201 5.07 .042 
47. Riis PT, Ring HC, Themstrup L, Jemec GB. The role of androgens and estrogens in hidradenitis suppurativa-a systematic review. Acta Dermatovenerol Croat. (2016) 24:239-49.

48. Esser C, Rannug A, Stockinger B. The aryl hydrocarbon receptor in immunity. Trends Immunol. (2009) 30:447-54. doi: 10.1016/j.it.2009.06.005

49. Hana A, Booken D, Henrich C, Gratchev A, Maas-Szabowski N, Goerdt S, et al. Functional significance of non-neuronal acetylcholine in skin epithelia. Life Sci. (2007) 80:2214-20. doi: 10.1016/j.lfs.2007.02.007

50. Nikota JK, Shen P, Morissette MC, Fernandes K, Roos A, Chu DK, et al. Cigarette smoke primes the pulmonary environment to IL-1 $\alpha / C X C R-2-$ dependent non-typeable Haemophilus influenzae-exacerbated neutrophilia in mice. J Immunol. (2014) 193:3134-45. doi: 10.4049/jimmunol.1302412

51. Qiu F, Liang CL, Liu H, Zeng YQ, Hou S, Huang S, et al. Impacts of cigarette smoking on immune responsiveness: up and down or upside down? Oncotarget. (2017) 8:268-84. doi: 10.18632/oncotarget.13613

52. Richards JL, Yap YA, McLeod KH, Mackay CR, Marino E. Dietary metabolites and the gut microbiota: an alternative approach to control inflammatory and autoimmune diseases. Clin Transl Immunology. (2016) 5:e82. doi: 10.1038/cti.2016.29.eCollection 2016

53. Kothari V, Galdo JA, Mathews ST. Hypoglycemic agents and potential anti-inflammatory activity. J Inflamm Res. (2016) 9:27-38. doi: 10.2147/JIR.S86917.eCollection 2016

54. Vossen AR, van Straalen KR, Prens EP, van der Zee HH. Menses and pregnancy affect symptoms in hidradenitis suppurativa: a cross-sectional study. J Am Acad Dermatol. (2017) 76:155-6. doi: 10.1016/j.jaad.2016.07.024

55. Eicheler W, Dreher M, Hoffmann R, Happle R, Aumuller G. Immunohistochemical evidence for differential distribution of 5 alpha-reductase isoenzymes in human skin. $T$ Br J Dermatol. (1995) 133:371-6. doi: 10.1111/j.1365-2133.1995.tb02663.x

56. Golbari NM, Porter ML, Kimball AB. Antiandrogen therapy with spironolactone for the treatment of hidradenitis suppurativa. J Am Acad Dermatol. (2019) 80:114-9. doi: 10.1016/j.jaad.2018.06.063

57. Hurley H. Axillary Hyperhidrosis, Apocrine Bromhidrosis, Hidradenitis Suppurativa, and Familial Benign Pemphigus: Surgical Approach. Dermatologic Surgery. New York, NY: Marcel Dekker. (1989) 729-39.

58. Sartorius K, Emtestam L, Jemec GB, Lapins J. Objective scoring of hidradenitis suppurativa reflecting the role of tobacco smoking and obesity. Br J Dermatol. (2009) 161:831-9. doi: 10.1111/j.1365-2133.2009.09198.x

59. Kimball AB, Jemec GB, Yang M, Kageleiry A, Signorovitch JE, Okun MM, et al. Assessing the validity, responsiveness and meaningfulness of the Hidradenitis Suppurativa Clinical Response (HiSCR) as the clinical endpoint for hidradenitis suppurativa treatment. Br J Dermatol. (2014) 171:143442. doi: 10.1111/bjd.13270

60. Alikhan A, Sayed C, Alavi A, Alhusayen R, Brassard A, Burkhart C, et al. North American clinical management guidelines for hidradenitis suppurativa: a publication from the United States and Canadian Hidradenitis Suppurativa Foundations: part II: topical, intralesional, and systemic medical management. J Am Acad Dermatol. (2019) 81:91-101. doi: 10.1016/j.jaad.2019.02.068

61. Andersen RK, Jemec GB. Treatments for hidradenitis suppurativa. Clin Dermatol. (2017) 35:218-24. doi: 10.1016/j.clindermatol.2016.10.018

62. Zouboulis CC, Bechara FG, Fritz K, Kurzen H, Liakou AI, Marsch WC, et al. S1 guideline for the treatment of hidradenitis suppurativa/acne inversa*(number ICD-10 L73. 2). J Dtsch Dermatol Ges. (2012) 10:S131. doi: 10.1111/j.1610-0387.2012.08006.x

63. Patel ZS, Hoffman LK, Buse DC, Grinberg AS, Afifi L, Cohen SR, et al. Pain, psychological comorbidities, disability, and impaired quality of life in hidradenitis suppurativa [corrected]. Curr Pain Headache Rep. (2017) 21:49. doi: 10.1007/s11916-017-0647-3

64. Jemec GB. Quality of life considerations and pain management in hidradenitis suppurativa. Semin Cutan Med Surg. (2017) 36:75-8. doi: 10.12788/j.sder.2017.016

65. Garcia-Martinez FJ, Vilarrasa Rull E, Salgado-Boquete L, Martorell A, Pascual JC, Hernandez-Martin A, et al. Intralesional corticosteroid injection for the treatment of hidradenitis suppurativa: a multicenter retrospective clinical study. J Dermatolog Treat. (2019) 29:1-5. doi: 10.1080/09546634.2019.1655524
66. Zouboulis CC, Bechara FG, Dickinson-Blok JL, Gulliver W, Horvath B, Hughes R, et al. Hidradenitis suppurativa/acne inversa: a practical framework for treatment optimization-systematic review and recommendations from the HS ALLIANCE working group. J Eur Acad Dermatol Venereol. (2019) 33:19-31. doi: 10.1111/jdv.15233

67. Fischer AH, Haskin A, Okoye GA. Patterns of antimicrobial resistance in lesions of hidradenitis suppurativa. J Am Acad Dermatol. (2017) 76:309-13.e2. doi: 10.1016/j.jaad.2016.08.001

68. Clemmensen OJ. Topical treatment of hidradenitis suppurativa with clindamycin. Int J Dermatol. (1983) 22:3258. doi: 10.1111/j.1365-4362.1983.tb02150.x

69. Jemec GB, Wendelboe P. Topical clindamycin versus systemic tetracycline in the treatment of hidradenitis suppurativa. J Am Acad Dermatol. (1998) 39:971-4. doi: 10.1016/s0190-9622(98)70272-5

70. Bettoli V, Zauli S, Borghi A, Toni G, Minghetti S, Ricci M, et al. Oral clindamycin and rifampicin in the treatment of hidradenitis suppurativaacne inversa: a prospective study on 23 patients. J Eur Acad Dermatol Venereol. (2014) 28:125-6. doi: 10.1111/jdv.12127

71. Gener G, Canoui-Poitrine F, Revuz JE, Faye O, Poli F, Gabison G, et al. Combination therapy with clindamycin and rifampicin for hidradenitis suppurativa: a series of 116 consecutive patients. Dermatology. (2009) 219:148-54. doi: 10.1159/000228334

72. Yazdanyar S, Boer J, Ingvarsson G, Szepietowski JC, Jemec GBE. Dapsone therapy for hidradenitis suppurativa: a series of 24 patients. Dermatology. (2011) 222:342-6. doi: 10.1159/000329023

73. Kaur MR, Lewis HM. Hidradenitis suppurativa treated with dapsone: a case series of five patients. J Dermatolog Treat. (2006) 17:2113. doi: 10.1080/09546630600830588

74. Verdolini R, Clayton N, Smith A, Alwash N, Mannello B. Metformin for the treatment of hidradenitis suppurativa: a little help along the way. J Eur Acad Dermatol Venereol. (2013) 27:1101-8. doi: 10.1111/j.1468-3083.2012.04668.x

75. Lee A, Fischer G. A case series of 20 women with hidradenitis suppurativa treated with spironolactone. Australas J Dermatol. (2015) 56:192-6. doi: 10.1111/ajd.12362

76. Mortimer PS, Dawber RP, Gales MA, Moore RA. A doubleblind controlled cross-over trial of cyproterone acetate in females with hidradenitis suppurativa. $\mathrm{Br} J$ Dermatol. (1986) 115:263-8. doi: 10.1111/j.1365-2133.1986.tb05740.x

77. Khandalavala BN, Do MV. Finasteride in hidradenitis suppurativa: a "male" therapy for a predominantly "female" disease. J Clin Aesthet Dermatol. (2016) 9:44-50.

78. Boer J, van Gemert MJP. Long-term results of isotretinoin in the treatment of 68 patients with hidradenitis suppurativa. J Am Acad Dermatol. (1999) 40:73-6. doi: 10.1016/s0190-9622(99)70530-x

79. Dicken CH, Powell ST, Spear KL. Evaluation of isotretinoin treatment of hidradenitis suppurativa. J Am Acad Dermatol. (1984) 11:5002. doi: 10.1016/s0190-9622(84)70199-x

80. Anderson MD, Zauli S, Bettoli V, Boer J, Jemec GB. Cyclosporine treatment of severe Hidradenitis suppurativa-A case series. J Dermatolog Treat. (2016) 27:247-50. doi: 10.3109/09546634.2015.1088128.

81. Nazary M, Prens EP, Boer J. Azathioprine lacks efficacy in hidradenitis suppurativa: a retrospective study of nine patients. Br J Dermatol. (2016) 174:639-41. doi: 10.1111/bjd.14086

82. Jemec GB. Methotrexate is of limited value in the treatment of hidradenitis suppurativa. Clin Exp Dermatol. (2002) 27:5289. doi: 10.1046/j.1365-2230.2002.11125.x

83. Hoffman LK, Ghias MH, Lowes MA. Pathophysiology of hidradenitis suppurativa. Semin Cutan Med Surg. (2017) 36:47-54. doi: 10.12788/j.sder.2017.017

84. Grant A, Gonzalez T, Montgomery MO, Cardenas V, Kerdel FA. Infliximab therapy for patients with moderate to severe hidradenitis suppurativa: a randomized, double-blind, placebo-controlled crossover trial. J Am Acad Dermatol. (2010) 62:205-17. doi: 10.1016/j.jaad.2009.06.050

85. Tzanetakou V, Kanni T, Giatrakou S, Katoulis A, Papadavid E, Netea MG, et al. Safety and efficacy of anakinra in severe hidradenitis suppurativa: a randomized clinical trial. JAMA Dermatol. (2016) 152:529. doi: 10.1001/jamadermatol.2015.3903 
86. Kimball AB, Kerdel F, Adams D, Mrowietz U, Gelfand JM, Gniadecki $\mathrm{R}$, et al. Adalimumab for the treatment of moderate to severe Hidradenitis suppurativa: a parallel randomized trial. Ann Intern Med. (2012) 157:846-55. doi: 10.7326/0003-4819-157-12-20121218000004

87. Kimball AB, Okun MM, Williams DA, Gottlieb AB, Papp KA, Zouboulis CC, et al. Two phase 3 trials of adalimumab for hidradenitis suppurativa. $N$ Engl J Med. (2016) 375:422-34. doi: 10.1056/NEJMoa1504370

88. Sotiriou E, Goussi C, Lallas A, Chovarda E, Apalla Z, Lazaridou E, et al. A prospective open-label clinical trial of efficacy of the every week administration of adalimumab in the treatment of hidradenitis suppurativa. J Drugs Dermatol. (2012) 11:S15-20.

89. Zouboulis CC, Okun MM, Prens EP, Gniadecki R, Foley PA, Lynde $\mathrm{C}$, et al. Long-term adalimumab efficacy in patients with moderate-tosevere hidradenitis suppurativa/acne inversa: 3-year results of a phase 3 open-label extension study. J Am Acad Dermatol. (2019) 80:609.e2. doi: 10.1016/j.jaad.2018.05.040

90. Adams DR, Yankura JA, Fogelberg AC, Anderson BE. Treatment of hidradenitis suppurativa with etanercept injection. Arch Dermatol. (2010) 146:501-4. doi: 10.1001/archdermatol.2010.72

91. Giamarellos-Bourboulis EJ, Pelekanou E, Antonopoulou A, Petropoulou H, Baziaka F, Karagianni V, et al. An open-label phase II study of the safety and efficacy of etanercept for the therapy of hidradenitis suppurativa. Br J Dermatol. (2008) 158:567-72. doi: 10.1111/j.1365-2133.2007. 08372.x

92. Tursi A. Concomitant hidradenitis suppurativa and pyostomatitis vegetans in silent ulcerative colitis successfully treated with golimumab. Dig Liver Dis. (2016) 48:1511-2. doi: 10.1016/j.dld.2016.09.010

93. Blok JL, Li K, Brodmerkel C, Horvatovich P, Jonkman MF, Horvath B. Ustekinumab in hidradenitis suppurativa: clinical results and a search for potential biomarkers in serum. Br J Dermatol. (2016) 174:83946. doi: 10.1111/bjd.14338

94. Gulliver WP, Jemec GB, Baker KA. Experience with ustekinumab for the treatment of moderate to severe hidradenitis suppurativa. J Eur Acad Dermatol Venereol. (2012) 26:911-4. doi: 10.1111/j.1468-3083.2011.0 4123.x

95. Santos-Perez MI, Garcia-Rodicio S, Del Olmo-Revuelto MA, PozoRoman T. Ustekinumab for hidradenitis suppurativa: a case report. Actas Dermosifiliogr. (2014) 105:720-2. doi: 10.1016/j.ad.2013.09.011

96. Sharon VR, Garcia MS, Bagheri S, Goodarzi H, Yang C, Ono Y, et al. Management of recalcitrant hidradenitis suppurativa with ustekinumab. Acta Derm Venereol. (2012) 92:320-1. doi: 10.2340/00015555-1229

97. Thorlacius L, Theut Riis P, Jemec GBE. Severe hidradenitis suppurativa responding to treatment with secukinumab: a case report. $\mathrm{Br} J$ Dermatol. (2018) 179:182-5. doi: 10.1111/bjd.15769

98. Schuch A, Fischer T, Boehner A, Biedermann T, Volz T. Successful treatment of severe recalcitrant hidradenitis suppurativa with the interleukin-17a antibody secukinumab. Acta Derm Venereol. (2018) 98:151-2. doi: 10.2340/00015555-2794

99. Glatt S, Helmer E, Haier B, Strimenopoulou F, Price G, Vajjah P, et al. First-in-human randomized study of bimekizumab, a humanized monoclonal antibody and selective dual inhibitor of IL-17A and IL-17F, in mild psoriasis. Br J Clin Pharmacol. (2017) 83:991-1001. doi: 10.1111/bc p.13185
100. Sun NZ, Ro T, Jolly P, Sayed CJ. Non-response to interleukin-1 antagonist canakinumab in two patients with refractory pyoderma gangrenosum and hidradenitis suppurativa. J Clin Aesthet Dermatol. (2017) 10:36-8.

101. Vossen A, van Doorn MBA, van der Zee HH, Prens EP. Apremilast for moderate hidradenitis suppurativa: results of a randomized controlled trial. J Am Acad Dermatol. (2019) 80:80-8. doi: 10.1016/j.jaad.2018.06.046

102. Leslie KS, Tripathi SV, Nguyen TV, Pauli M, Rosenblum MD. An open-label study of anakinra for the treatment of moderate to severe hidradenitis suppurativa. J Am Acad Dermatol. (2014) 70:243-51. doi: 10.1016/j.jaad.2013.09.044

103. Kovacs M, Podda M. Guselkumab in the treatment of severe hidradenitis suppurativa. J Eur Acad Dermatol Venereol. (2019) 33:e140-1. doi: 10.1111/jdv.15368

104. Casseres RG, Kahn JS, Her MJ, Rosmarin D. Guselkumab in the treatment of hidradenitis suppurativa: a retrospective chart review. J Am Acad Dermatol. (2019) 81:265-7. doi: 10.1016/j.jaad.2018.12.017

105. Takahashi K, Yanagi T, Kitamura S, Hata H, Imafuku K, Iwami D, et al. Successful treatment of hidradenitis suppurativa with rituximab for a patient with idiopathic carpotarsal osteolysis and chronic active antibody-mediated rejection. J Dermatol. (2018) 45:e116-7. doi: 10.1111/1346-8138.14144

106. Alharbi Z, Kauczok J, Pallua N. A review of wide surgical excision of hidradenitis suppurativa. BMC Dermatol. (2012) 12:9. doi: 10.1186/1471-5945-12-9

107. Mitchell KM, Beck DE. Hidradenitis suppurativa. Surg Clin North Am. (2002) 82:1187-97. doi: 10.1016/s0039-6109(02)00060-9

108. Slade DE, Powell BW, Mortimer PS. Hidradenitis suppurativa: pathogenesis and management. Br J Plast Surg. (2003) 56:45161. doi: 10.1016/s0007-1226(03)00177-2

109. Danby FW, Hazen PG, Boer J. New and traditional surgical approaches to hidradenitis suppurativa. J Am Acad Dermatol. (2015) 73:S625. doi: 10.1016/j.jaad.2015.07.043

110. Kohorst JJ, Baum CL, Otley CC, Roenigk RK, Schenck LA, Pemberton $\mathrm{JH}$, et al. Surgical management of hidradenitis suppurativa: outcomes of 590 consecutive patients. Dermatol Surg. (2016) 42:1030-40. doi: 10.1097/DSS.0000000000000806

111. van der Zee HH, Prens EP, Boer J. Deroofing: a tissue-saving surgical technique for the treatment of mild to moderate hidradenitis suppurativa lesions. J Am Acad Dermatol. (2010) 63:475-80. doi: 10.1016/j.jaad.2009.12.018

112. Suppa M, D’Hondt V, Daxhelet M, Del Marmol V. Step by step surgery: a new therapeutic proposal for hidradenitis suppurativa. Exp Dermatol. (2019) 28(Suppl.2):5-55. doi: 10.1111/exd.13893

Conflict of Interest: The authors declare that the research was conducted in the absence of any commercial or financial relationships that could be construed as a potential conflict of interest.

Copyright (C) 2020 Seyed Jafari, Hunger and Schlapbach. This is an open-access article distributed under the terms of the Creative Commons Attribution License (CC BY). The use, distribution or reproduction in other forums is permitted, provided the original author(s) and the copyright owner(s) are credited and that the original publication in this journal is cited, in accordance with accepted academic practice. No use, distribution or reproduction is permitted which does not comply with these terms. 